\title{
The Effectiveness of Offensive tactical activity for the Numerical Change Cases during Competition in Handball
}

\author{
Prof. Yasser Mohamed Hassan Dabbour ${ }^{1}$ \\ Prof. Wafaa Mohamed Abdel-Meguid El-Kotamy² \\ Dr. Tarek Lotfy Zahran ${ }^{3}$ \\ Researcher / Wagih Ahmed Korany ${ }^{4}$
}

\begin{abstract}
:
The study aims to identify the effectiveness of offensive tactical activity according to the numerical change cases and its productivity during the game's periods in light of the law modifications regarding the involvement of the goalkeeper's substitute. The research sample included 76 games of the 2017 World Men's Championship in France, the twenty-second edition, using a form prepared by the researchers in order to observe the visual scoring of the matches of the research sample and the results showed that there is a difference between the effectiveness of the offensive tactical activity in the participating teams, according to the numerical change cases in addition to the variation of the offensive tactical activity productivity during the match between the participating teams. The most notable recommendations were: increasing the training to master the formations and offensive patterns that occur in the different situations in the game, the development of individual and group offensive performance, depending on the action instead of the reaction to attract the defender's attention outside the formation finishing zone in addition to training the players to take advantage of the numerical changes by designing compulsory training and technical positions during training and the friendly matches to implement them.
\end{abstract}

Keywords: offensive tactical activity, effectiveness, numerical change, handball

\footnotetext{
${ }^{1}$ Professor of handball training, Sport Games Training Department, Faculty of Physical Education for Boys, Alexandria University.

${ }^{2}$ Professor of handball training, Sport Training and Kinesiology Department, Faculty of Physical Education for Girls, Alexandria University.

${ }^{3}$ Lecturer, Sport Games Training Department, Faculty of Physical Education for Boys, Alexandria University.

${ }^{4}$ Researcher, Sport Games Training Department, Faculty of Physical Education for Boys, Alexandria University.
} 


\section{Study introduction and problem:}

Nowadays there is a great development in sports achievements as a result of the scientific research and linking the physical education sciences with the other science branches, and this only happens by using the available quantitative numbers provided by the quantitative analysis. This was subsequently confirmed by Vuleta et al. (2012) that handball is characterized by a set of typical and atypical competitive positions during the game, therefore we need extensive knowledge of specific positions in the game and the effectiveness of each player in the competitive situations and positions. (23:7)

Therefore, Valeriy et al. (2016) note that improving the competitive activity is linked to the rules modifications, with increased mental and physical effort that makes the demands increase to the tactical training for the handball players since the absence of tactical level reduces the effectiveness of technical and physical capabilities and also reduces the possibility of achieving higher sports results. (29:77)

The researchers think that the continuous changes and modifications in the legal rules always develop and improve the competitive activity, which in turn is reflected in the development of the tactical aspects, and with the observation of certain successful teams who are always top ranked, it was necessary to know their capabilities to identify the reasons for their superiority.

Felicia and Beatrice (2015) state that the technical and tactical performances are not separate, but they a combined form in most of the game, since they greatly vary from a training phase to another even in the play situations. (24:83-85)

The researchers show that the tactical performance which has become the strategy of the team that focuses on the mistakes of the competing teams and creates advantages for the team that depend on two main elements, which are reaching the goal and integrating with the physical and technical capabilities of the players and adapt to the different tactical positions with monitoring and analysis of the tactical activity as a complex process to obtain relevant information to the team and the top-level competing teams.

Mohamed Khaled Hammouda and Hala Youssef Mandour (2004) note that the effectiveness of the tactical formations depends on what the player possesses of techniques and in order for the player to be effective he must be fully aware of the specialized tactical duties of his position before he involve these duties to the teamwork when implementing the plan, since the tactical activity that are implemented within the lineup content are carried out through time-bound cooperative phases and each player has his role to play within these tactical activities. This individual role is a pattern of action that each member of the team must perform perfectly. (15:4)

Recently, and especially after the approval of the new legal modifications issued by the International Handball Federation and generalizing them to all confederations, and then the national federations, since the success of the tactical aspect according to these 
modifications is considered a success for the entire team, since it decides the destination of the attack, and includes one of its clauses for the goalkeeper's substitute during the attack and involving an additional player to replace the goalkeeper without changing clothes, but he is not allowed to return to the goal area to become a goalkeeper, and he must go out and switch with the legal goalkeeper, these modifications contributed to the development of the game, the acceleration of the pace of games and prevent it to be a slow and stereotypical game.

The researchers believe that the time has come to use advanced methods that enable the coaches to obtain adequate information of their own teams as well as the competing teams, so that they benefit them in improving the preparation and leadership processes for their teams in competitions and sports tournaments by analyzing the offensive performance of the different teams and identifying the recent development in tactical aspects and how to deal with the numerical change cases faced by the different teams imposed by the match conditions. The research problem here focuses on identifying the offensive performance by studying the effectiveness of the offensive tactical activity according to the numerical change cases as well as its productivity during the game and its effect on the results of the 2017 World Men's Handball Championship matches, which was held in France, where the researchers observed the superiority of some teams over their competitors in the number of the scored goals and thus winning the match.

\section{Research objectives:}

Identifying:

1- The effectiveness of the offensive tactical activity according to the numerical change cases in light of the law modifications regarding the involvement of the goalkeeper's substitute and its relationship to the productivity of the participating teams.

2- The effectiveness and productivity of the offensive tactical activity during the game in light of the law's modifications regarding the involvement of the goalkeeper's substitute for the participating teams.

\section{Research questions:}

1- What is the effectiveness of offensive tactical activity according to the numerical change cases in light of the law modifications regarding the involvement of the goalkeeper's substitute and its relationship to the productivity of the participating teams?

2- Is there a variation in the effectiveness and productivity of the offensive tactical activity during the game in light of the modifications of the law regarding the involvement of the goalkeeper's substitute for the participating teams? 


\section{Research terminology:}

\section{Offensive tactical activity:}

Yasser Hassan Dabbour (2015) describes it as the wealth that the team possesses including the "dual" or "complex" patterns or group tactical formations that require collective motor actions. (22:203)

\section{Effectiveness:}

Yasser Hassan Dabbour (2015) defined it as the observation of the actual and effective performance, as well as the indicators and levels of effectiveness and the levels of achieving the performance objective. (22:204)

\section{Study procedures:}

\section{Research methodology:}

The researchers used the descriptive survey method.

\section{Study community:}

The research community consists of the matches of the 2017 World Men's Handball Championship in France, the twenty-second edition, which included (76) games.

\section{Study sample:}

The researchers divided the sample as shown in the following table:

\section{Table (1) Pilot studies and main study}

\begin{tabular}{|c|c|c|c|}
\hline Description & First pilot study & Second pilot study & Main study \\
\hline $\begin{array}{l}\text { Number of } \\
\text { matches }\end{array}$ & \multirow{3}{*}{$\begin{array}{l}\text { Submitting the forms to the } \\
\text { experts to determine the } \\
\text { nature and effectiveness of the } \\
\text { offensive tactical } \\
\text { performance, as well as the } \\
\text { lineups and the quantity of } \\
\text { involvement of the } \\
\text { goalkeeper's substitute }\end{array}$} & 2 & 76 games \\
\hline Championship & & $\begin{array}{l}2016 \text { Summer Olympics, } \\
\text { Rio de Janeiro, Brazil }\end{array}$ & $\begin{array}{l}\text { World Championship } \\
\text { in France, } 2017\end{array}$ \\
\hline $\begin{array}{l}\text { Implementing } \\
\text { date }\end{array}$ & & $\begin{array}{l}\text { From } 1 / 10 / 2019 \text { to } \\
10 / 10 / 2019\end{array}$ & $\begin{array}{l}\text { From } 3 / 11 / 2019 \text { to } \\
13 / 2 / 2020\end{array}$ \\
\hline
\end{tabular}

Table (1) illustrates the first and second pilot studies, the main study, and the characteristics of each will be clarified sample in its own place

The main study teams were divided into 3 levels according to the final ranking of the tournament, as follows:

\section{Level (A):}

Teams ranked from 1 to 8 .

\section{Level (B):}

Teams ranked from 9 to 16 . 


\section{Level (C):}

Teams ranked from 17-24.

Table (2) Final ranking of the participating teams in the 2017 World Handball Championship in France

\begin{tabular}{|c|c|c|c|}
\hline S. & Team & $\overline{\text { Rank }}$ & Level \\
\hline 1 & France & $1^{\mathrm{st}}$ & \multirow{8}{*}{ Level (A) } \\
\hline 2 & Norway & $2^{\text {nd }}$ & \\
\hline 3 & Slovenia & $3^{\text {rd }}$ & \\
\hline 4 & Croatia & $4^{\text {th }}$ & \\
\hline 5 & Spain & $5^{\text {th }}$ & \\
\hline$\overline{c 6}$ & 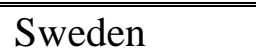 & $\frac{6^{6^{\text {th }}}}{}$ & \\
\hline 7 & Hungary & $7^{\text {th }}$ & \\
\hline 8 & Qatar & $8^{\text {th }}$ & \\
\hline 9 & Germany & $9^{\text {th }}$ & \multirow{8}{*}{ Level (B) } \\
\hline$\overline{c 10}$ & Denmark & $10^{\text {th }}$ & \\
\hline 11 & Belarus & $11^{\text {th }}$ & \\
\hline 12 & Russia & $12^{\text {th }}$ & \\
\hline 13 & Egypt & $13^{\text {th }}$ & \\
\hline 14 & Iceland & $14^{\text {th }}$ & \\
\hline 15 & Macedonia & $15^{\text {th }}$ & \\
\hline 16 & Brazil & $16^{\text {th }}$ & \\
\hline 17 & Poland & $17^{\text {th }}$ & \multirow{8}{*}{ Level (C) } \\
\hline 18 & Argentina & $18^{\text {th }}$ & \\
\hline 19 & Tunisia & $19^{\text {th }}$ & \\
\hline 20 & Saudi Arabia & $20^{\text {th }}$ & \\
\hline 21 & $\overline{\text { Chile }}$ & $21^{\mathrm{st}}$ & \\
\hline 22 & Japan & $22^{\text {nd }}$ & \\
\hline 23 & Bahrain & $23^{\text {rd }}$ & \\
\hline 24 & Angola & $24^{\text {th }}$ & \\
\hline
\end{tabular}

Table (2) shows the number of participating teams and their final ranking in the championship according to match statistics, and they were (24) teams. 


\section{Data collection tools:}

First: Scientific references and related studies:

\section{Second: Data registration form:}

\section{Steps of designing the form:}

\section{1- Determining the objective:}

The objective of the form was determined to collect the quantitative information on the performance of the teams:

1- The effectiveness of the numerical change cases for each level and its effect on the results of the matches

2- The effectiveness of the offensive tactical activity according to the numerical change cases for each level and its effect on the results of the matches

\section{2- Scientific transactions for the analysis forms:}

\section{First: Validity:}

The researchers calculated the validity coefficient of the analysis form in two ways:

\section{1- Content validity:}

The researchers showed the initial analysis forms, attachments (1) and (2), and the data registration form, attachment (3), to (10) experts specialized in the handball field in order to give their opinion regarding the variables and clarify the goal including them to ensure their validity. The percentages of the experts' opinions on the analysis form of the variables under discussion ranged between $(50 \%-100 \%)$, and the variables that got less than $90 \%$ of the total opinions were (2), while the variables that got $90 \%$ or more of the total opinions were (8).

\section{2- Logical validity:}

The researchers conducted an integrated and analytical study of references, periodicals and related studies (1), (2), (3), (4), (5), (7), (8), (11), (18) that dealt with the performance analysis in handball matches in general and the offensive performance in particular.

\section{3- Reliability coefficient:}

The researchers calculated the reliability coefficient of the two forms by calculating the Chi coefficient by two analysts, on a sample consisting of (2) matches, which were played in (2016 Rio Olympics). The results of the differences between the first and the second applications showed that there are no statistically significant differences between the two applications, where the calculated value of squared Chi was less than the tabular level (0.05), which confirms that the form is reliable. 


\section{Second: Pilot studies:}

The researchers conducted two pilot studies in order to identify the variables of the study and the difficulties that may be encountered during the conduct of the main study to try to avoid and overcome them.

\section{First pilot study:}

The researchers presented the two forms to the experts in the period from Sunday, 1/9/2019 to Thursday, 19/9/2019.

\section{Objectives of the first pilot study:}

- Determining the variables related to the offensive tactical activity that influences the results of the matches

- Identifying the difficulties that the researcher may encounter during the observation

\section{Second pilot study:}

The study was conducted from Tuesday, 1/10/2019 to Thursday 10/10/2019 and the sample included (2) matches from the research community and from outside the original sample.

\section{Objectives of the second pilot study:}

- Calculating the scientific transactions of the form

- Avoiding the negative aspects of the first pilot study which was focused on the large quantity of data

- Making sure that the data registration form is valid and easy to use

- Making sure of the validity and ease of use of the data registration forms

- Checking the validity of the tools and devices used

\section{Third: Hardware and tools:}

1- A high-tech computer

2- Software to compress the matches

3- CDs to copy the matches of the research sample

The researchers collected the data and compressed them into tables, in preparation for the statistical processing.

\section{Fourth: Main study:}

The researchers collected (76) matches from the matches of the 2017 World Men's Handball Championship, and this study was conducted from Sunday 3/11/2019 to Thursday 13/2/2020. 


\section{Fifth: Statistical treatments:}

- Arithmetic mean

- Standard deviation

- Frequency

- Percentage

- Cross tabulation

- Efficiency equation

- Chi squared

Presentation and discussion of the results:

First: Presentation of the results:

Table (5) Effectiveness of the offensive tactical performance according to the numerical change cases for the participating teams

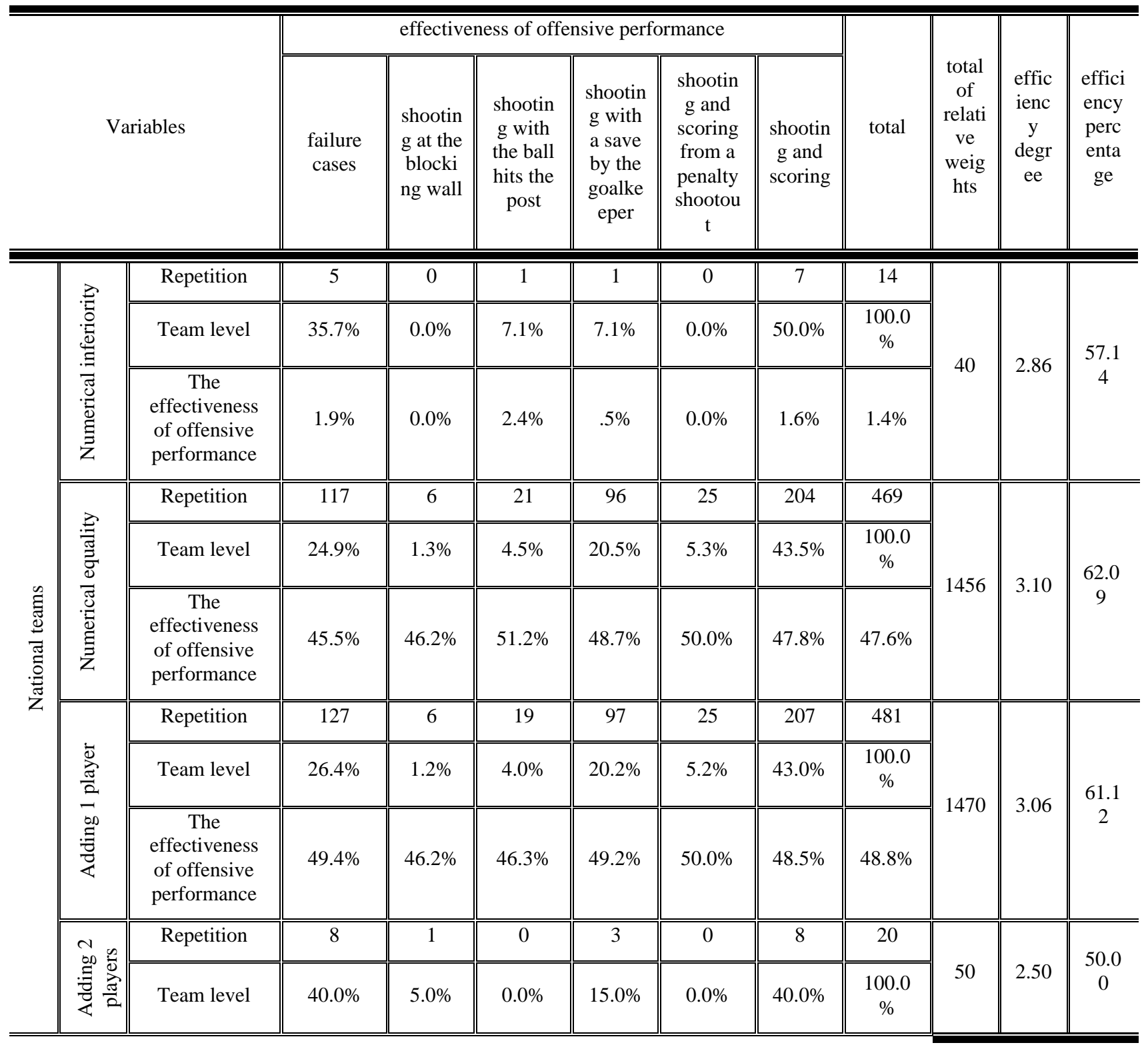




\begin{tabular}{|c|c|c|c|c|c|c|c|c|c|c|c|}
\hline & $\begin{array}{c}\text { The } \\
\text { effectiveness } \\
\text { of offensive } \\
\text { performance }\end{array}$ & $3.1 \%$ & $7.7 \%$ & $0.0 \%$ & $1.5 \%$ & $0.0 \%$ & $1.9 \%$ & $2.0 \%$ & & & \\
\hline \multirow{3}{*}{ total } & Repetition & $\begin{array}{c}\text { Repetitio } \\
n\end{array}$ & 13 & 41 & 197 & 50 & 427 & 985 & \multirow{3}{*}{3021} & \multirow{3}{*}{3.07} & \multirow{3}{*}{$\begin{array}{c}61.3 \\
4\end{array}$} \\
\hline & Team level & $\begin{array}{l}\text { Team } \\
\text { level }\end{array}$ & $1.3 \%$ & $4.2 \%$ & $20.0 \%$ & $5.1 \%$ & $43.4 \%$ & $\begin{array}{c}100.0 \\
\%\end{array}$ & & & \\
\hline & $\begin{array}{l}\text { The } \\
\text { effectiveness } \\
\text { of offensive } \\
\text { performance }\end{array}$ & $\begin{array}{l}\text { The } \\
\text { effective } \\
\text { ness of } \\
\text { offensive } \\
\text { performa } \\
\text { nce }\end{array}$ & $\begin{array}{c}100.0 \\
\%\end{array}$ & $100.0 \%$ & $\begin{array}{c}100.0 \\
\%\end{array}$ & $100.0 \%$ & $\begin{array}{c}100.0 \\
\%\end{array}$ & $\begin{array}{c}100.0 \\
\%\end{array}$ & & & \\
\hline
\end{tabular}

Table (5) illustrates the effectiveness of the offensive tactical performance according to the numerical change cases for the participating teams, the highest efficiency degree was 3.10 and $62.09 \%$ for the numerical equality cases and the lowest efficiency degree was for the cases of adding two players with 2.50 and $50.00 \%$, while the average total efficiency of the participating teams was 3.07 and $61.34 \%$. 
Table (6) Effectiveness of offensive tactical performance according to the numerical change cases for the (A) level teams

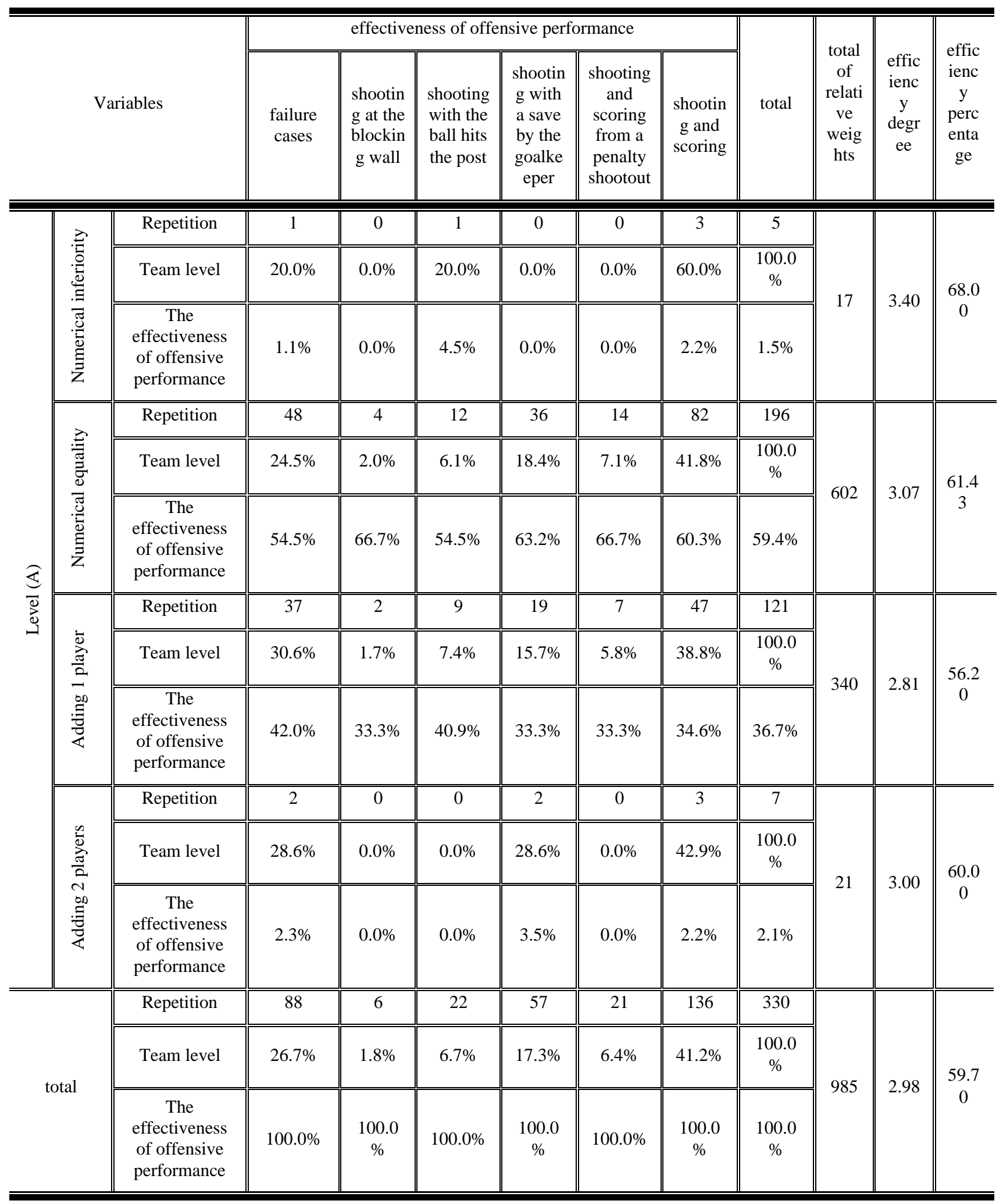

Table (6) illustrates the effectiveness of offensive tactical performance according to the numerical change cases for the (A) level teams, the highest efficiency degree was 3.40 and $68.00 \%$ for the cases of numerical inferiorities and the lowest efficiency degree was 
for the cases of adding one player with 2.81 and $56.20 \%$ while the average total efficiency was 2.98 and $59.70 \%$. 
Table (7) Effectiveness of offensive tactical performance according to the numerical change cases for the $(B)$ level teams

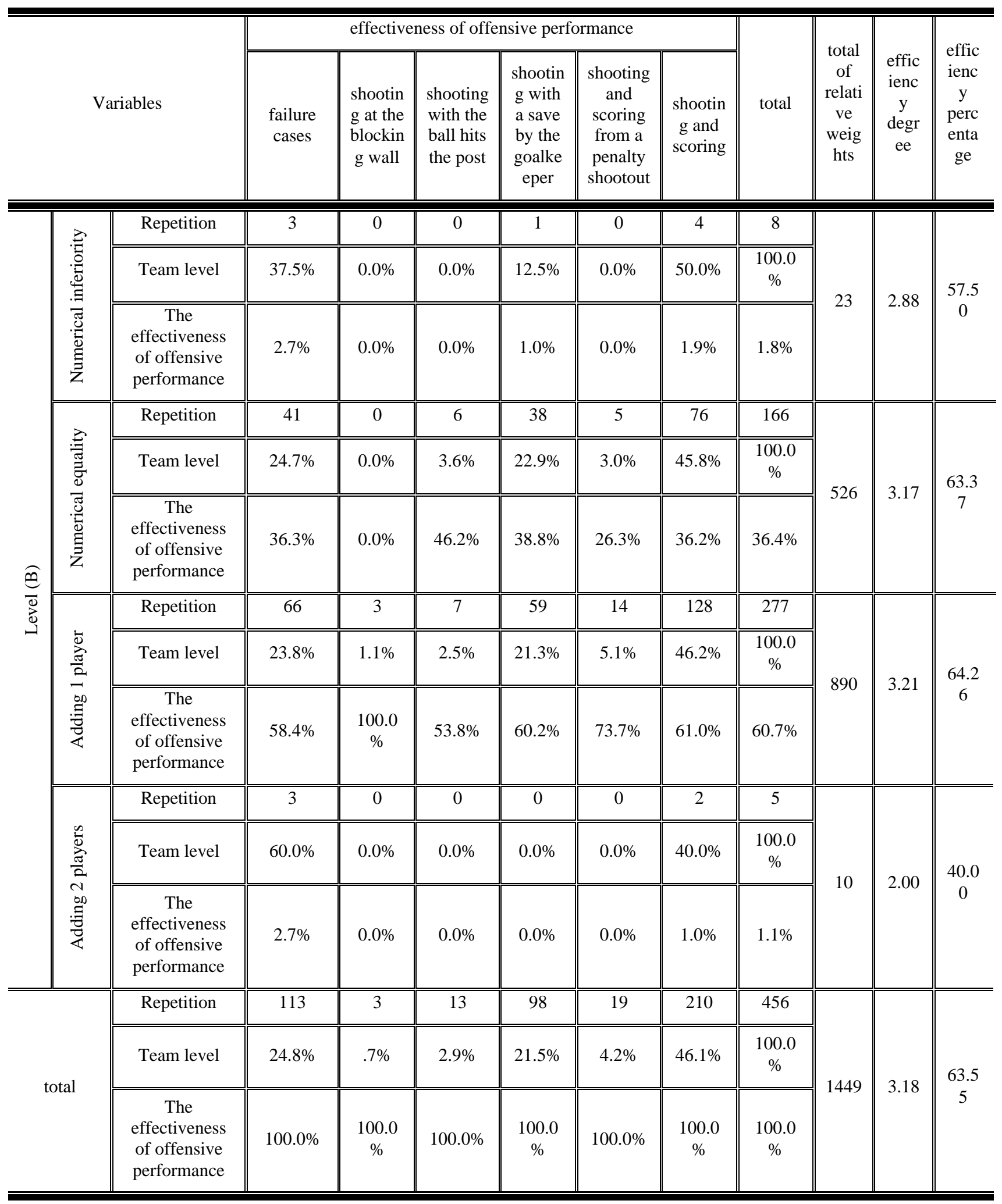

Table (7) illustrates the effectiveness of offensive tactical performance according to the numerical change cases for the (B) level teams and the highest efficiency degree was 3.21 and $64.26 \%$ for the cases of numerical increase by one player and the lowest 
efficiency degree of the cases of adding one player with 2.00 and $40.00 \%$ while the average total efficiency was 3.18 and $63.55 \%$. 
Table (8) Effectiveness of offensive tactical performance according to the numerical change cases for the $(C)$ level teams

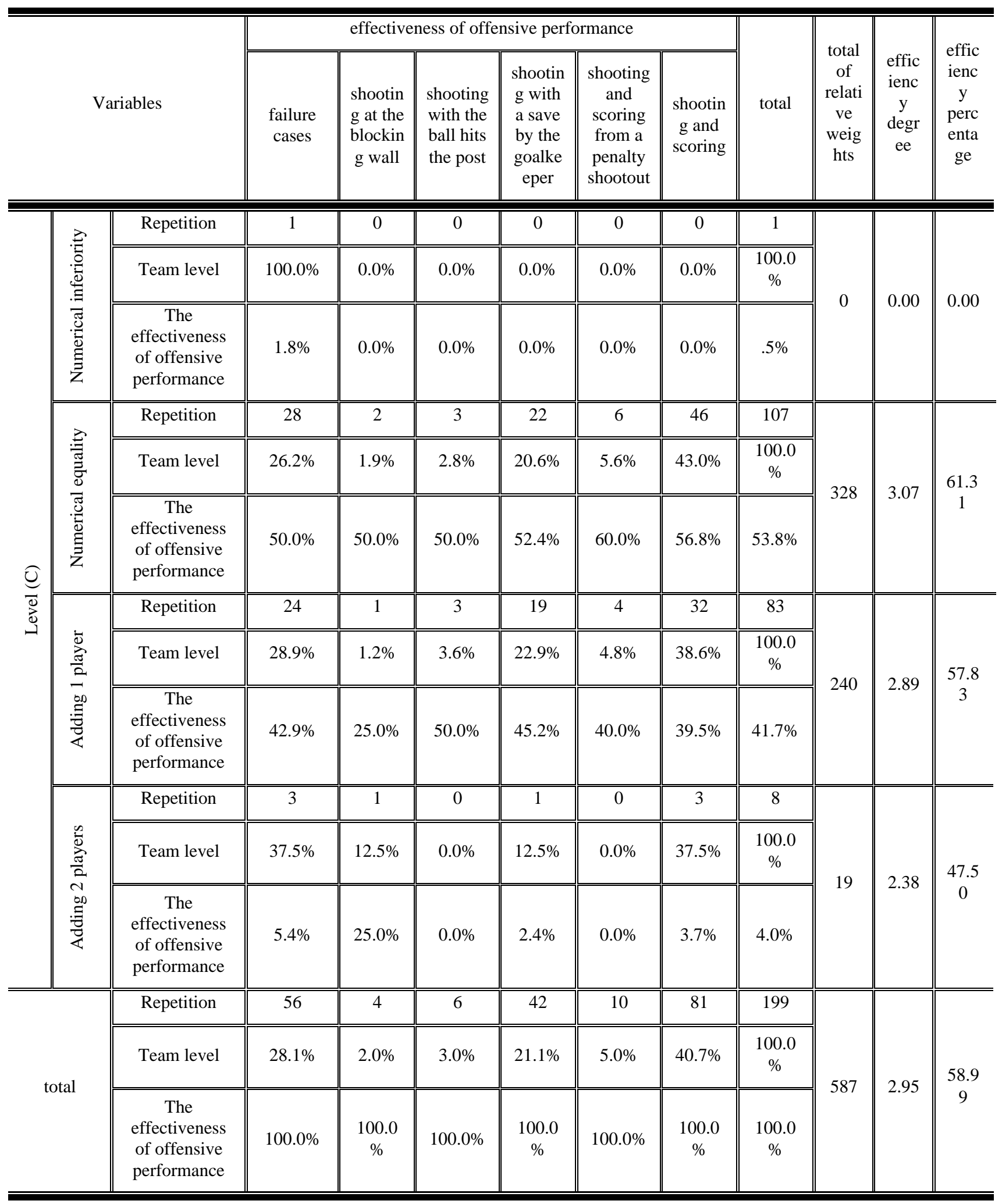

Table (8) illustrates the effectiveness of offensive tactical performance according to the numerical change cases for the (C) level teams and the highest efficiency degree was 3.07 and $61.31 \%$ for the numerical equality cases and the lowest efficiency degree was 
for the numerical inferiorities with zero and zero\%, while the average total efficiency of the teams level was 2.95 and $58.99 \%$. 
Table (9) Effectiveness of offensive tactical performance according to the match periods for the participating teams

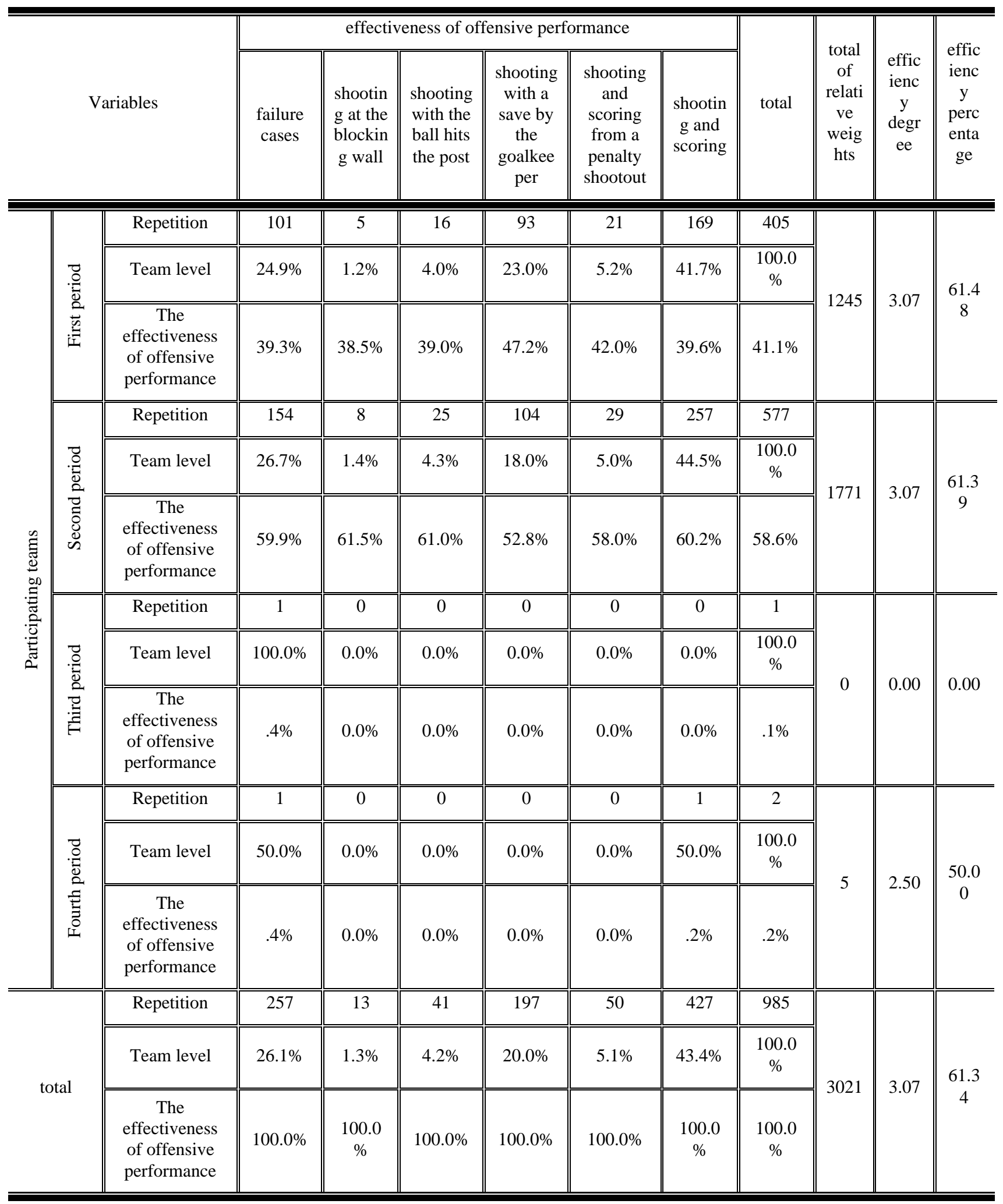

Table (9) illustrates the effectiveness of offensive tactical performance according to the match periods for the participating teams and the highest efficiency degree was 3.07 and $61.48 \%$ during the first and second periods while the lowest efficiency degree was zero 
and zero\% during the third additional period while the average total efficiency of the participating teams was 3.07 and $61.34 \%$. 
Table (10): The effectiveness of the tactical performance according to the match periods for the (A) level teams

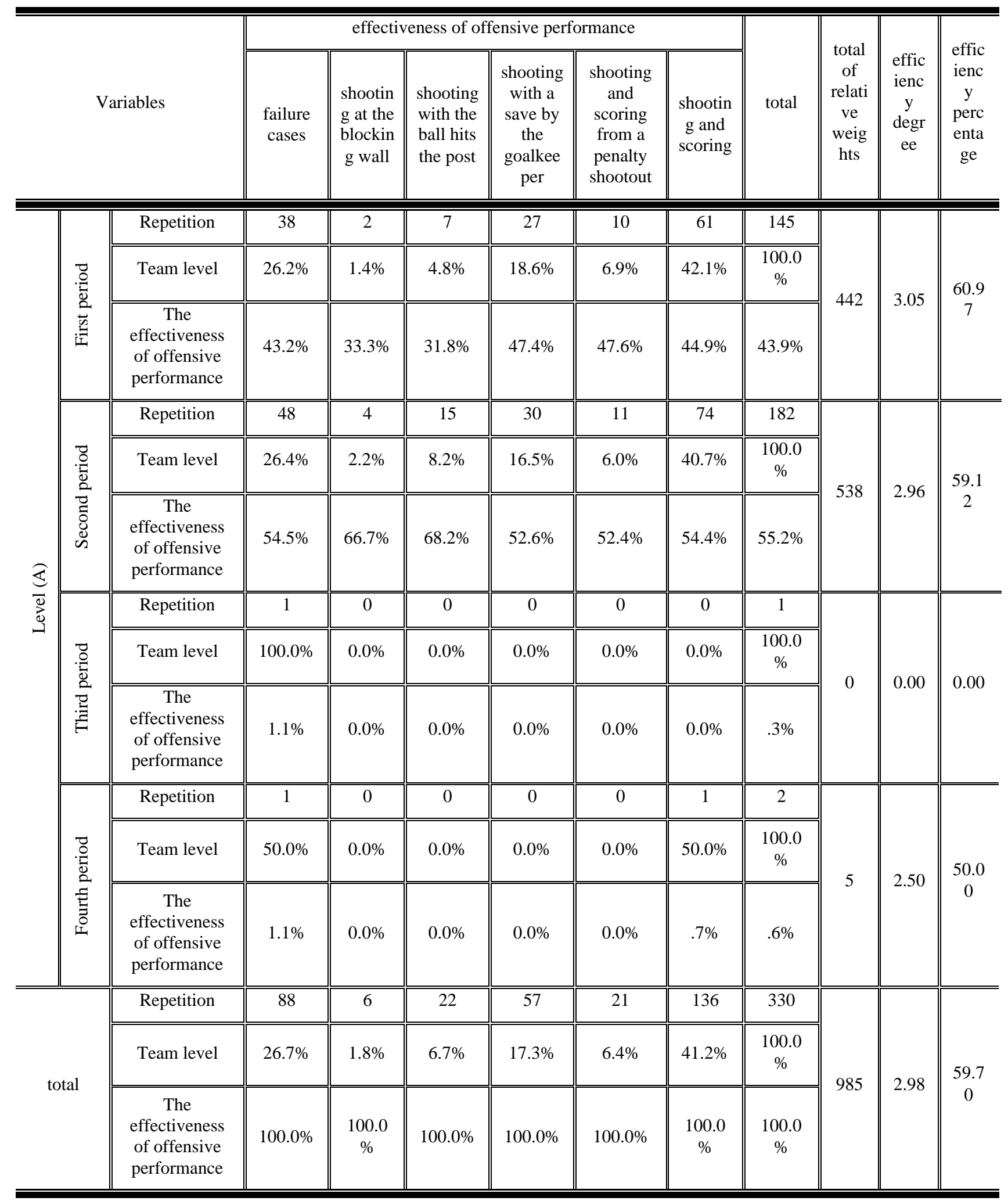

Table (10) illustrates the effectiveness of the tactical performance according to the match periods for the (A) level teams, the highest efficiency degree was 3.05 and $60.97 \%$ during the first period while the lowest efficiency degree was zero and zero\% 
during the third additional period while the average total efficiency was 2.98 and $59.70 \%$. 
Table (11) Effectiveness of the tactical performance according to the match periods for the (B) level teams

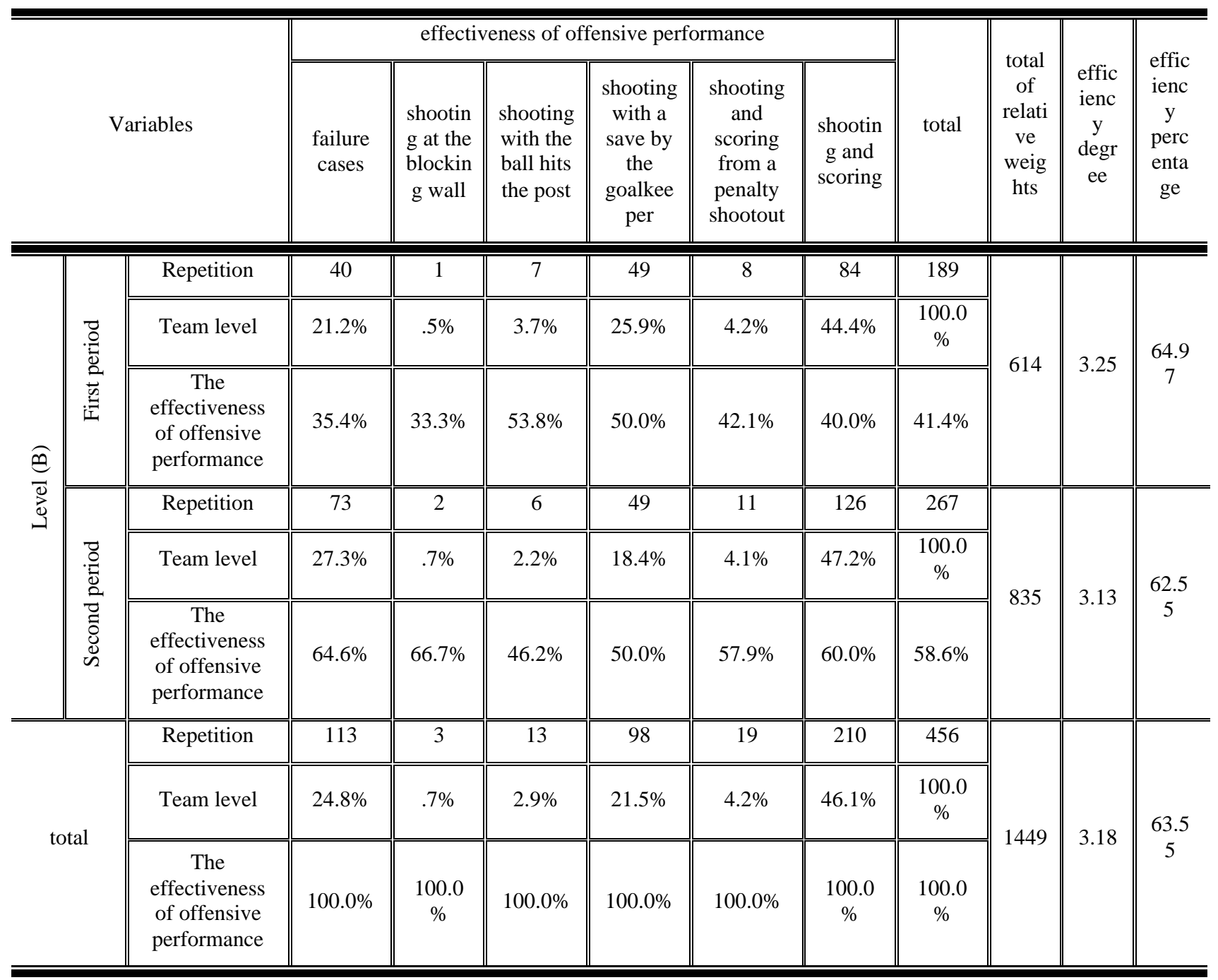

Table (11) illustrates the effectiveness of the tactical performance according to the match periods for the (B) level teams, the highest efficiency degree was 3.25 and $64.97 \%$ during the first period while the lowest efficiency degree was 3.13 and $62.55 \%$ during the second period while the average total efficiency was 3.18 and $63.55 \%$. 
Table (12): The effectiveness of the tactical performance according to the match periods for the $(C)$ level teams

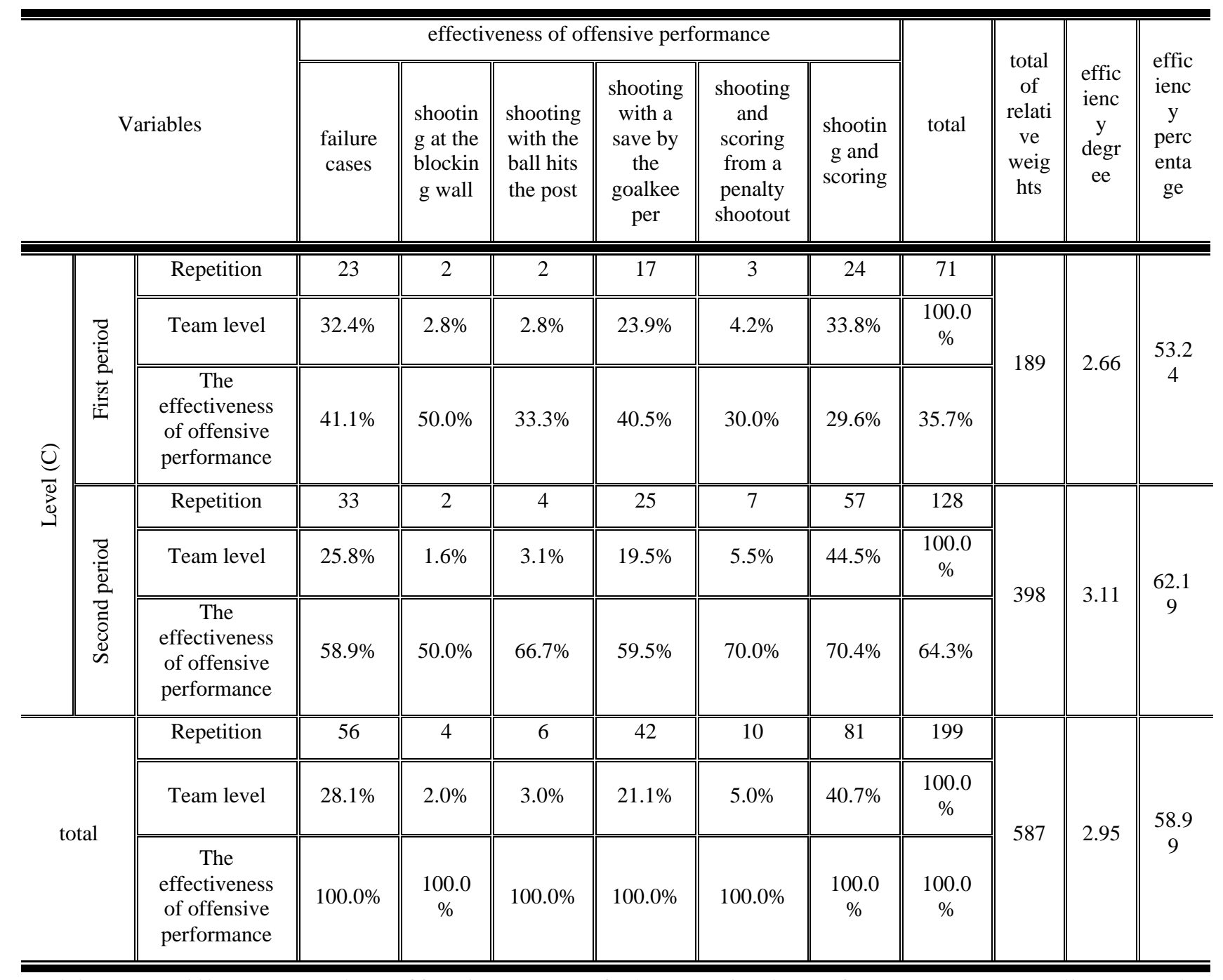

Table (12) illustrates the effectiveness of the tactical performance according to the match periods for the (C) level teams, the highest efficiency degree was 3.11 and $62.19 \%$ during the second period, and the lowest efficiency degree was 2.66 and $53.24 \%$ during the first period while the average total efficiency was 2.95 , or $58.99 \%$. 


\section{Second, discussion of the results:}

After presenting the findings through the statistical treatments, the researchers will discuss them by answering the research questions.

Answer of the first question:

\section{What is the effectiveness of offensive tactical activity according to the numerical change cases and the most influential in the matches?}

When comparing the teams of the three levels according to the effectiveness and their effect on the results of the matches, we find the following:

Table (5) shows that the numerical change cases in all preliminary and final rounds for all teams throughout the tournament, there were 985 cases varied between the numerical inferiority and equality, and adding one or two players. 'Adding one player' came at the first place with $48.8 \%$ out of the total percentage of the tournament cases with an efficiency degree of 3.06 and $61.12 \%$, and in the last place came the numerical inferiorities cases by $1.4 \%$ out of the total percentage of the tournament cases with an efficiency degree of 2.86 and $57.14 \%$.

Table (6), (7) and (8) show that the efficiency degree and percentage for the teams of the three levels according to the efficiency degree in the cases of numerical change in general, whether numerical inferiority or numerical equality or adding one or two players and their effect on the game and match result, and the offensive tactical performance in the case of numerical inferiority was in favor to the (A) level teams with an efficiency degree of 3.40 and $68 \%$, while the offensive tactical performance in achieving the numerical equality case was in favor to the (B) level teams with an efficiency degree of 3.17 and $63.37 \%$, the offensive performance in the case of adding one player was in favor to the (B) level teams with an efficiency degree of 3.21 and $64.26 \%$, while the offensive tactical performance in the case of adding two players was in favor to the (A) level teams with an efficiency degree of 3.00 and $60 \%$.

We notice that the teams of the three levels have taken advantage of the legal modifications and in close rates regardless of the numerical change cases between inferiority, equality or increase with the superiority of the (B) level teams, which indicates that the players possess notable techniques and are thus more trained and focused on carrying out the tactical duties in all circumstances as well as fast adaptation with the temporary numerical tactical situation, and some teams, such as the (A) level teams, used a variety of forms of tactical activities in cases of numerical inferiorities in an attempt to compensate for that inferiority and retain the ball for the longest possible time but with the numerical equality and increasing the number of players with one player, the activity diversified with the increase in the number of cases in order to increase the speed of performance and complete the match. Increasing the number of players with two strikers, the advantage was for the (A) level teams over the number of defenders by finding the defensive gaps and creating playing areas, but the performance decreased somewhat markedly for the $(\mathrm{C})$ level players, this may be due to the lack of 
techniques and counteractions as well as the individual capabilities of the players, as the player has various forms of performance, since the technique and its similarity with most play situations increases the player's ability to implement the assigned duties, which achieves a fast performance in terms of preparing and executing the attack and finishing it, and this is clear from the differences between the three levels when compared to each other according to the numerical change cases in general, whether inferiority, equality or numerical increase by one or two players.

This conforms to the results of the studies of Aly El-Beik and Shaaban Ibrahim (1995), Mohamed Keshk and Amrallah El-Bossati" (2004), where they concluded that the players' possession of various forms of complex tactical performances and use them according to the changing situations of the match allows them to choose the best of them and increases their abilities and then achieving the distinguished performance quickly with accuracy and compatibility as the various playing positions in handball impose on the players the use of complex forms, so it is important to use training forms that are close to the actual competition since the individual tactical performance in handball is characterized by a set of combined techniques that the player performs according to the requirements of the situation depending on the physical, technical and tactical capabilities. These requirements are always installed in motor sentences, so the training processes must be organized so that the player is able to adapt to the motor stress in order to achieve the minimum amount of time, idealism, and maximum speed in performance to attain the best achievement. (12:67), (17:114).

In world championships, the attack has become dependent on action, not reaction, to attract the defender's attention outside the formation finishing zone or to commit a legal fault to get a penalty throw. However, it was obvious that there were some teams that tended to prepare, build and end attacks using different tactical formations to confront some stable and slow situations with easy resist nature. These teams switched their tactical lineups due to the nature of the tactical situation, which requires training in some for the tactical lineups.

\section{What is the effectiveness and productivity of the offensive tactical performance of the teams, the study sample during the game?}

The results of Table (9), (10), (11), (12) showed that there are no differences between the teams of the first, second and third levels in the degree and percentage of the effectiveness of the tactical performance according to the attempts of these teams against the goals of the components and their goal scoring, when looking at the level teams. The (A) level teams' efficiency degree in the first period was 3.05 and $60.97 \%$, while in the second period was 2.96 and $59.12 \%$. The (B) level teams' efficiency degree in the first period was 3.25 and $64.97 \%$, while in the second period was 3.13 and $62.55 \%$. The (C) level teams' efficiency degree in the first period was 2.66 and $53.24 \%$, while in the second period was 3.11 points and $62.19 \%$.

The researchers attribute the lack of differences between these teams and the resemblance in the degree and percentage of efficiency, due to the fact that the players 
have reached a level of tactical maturity that enables them to deal with the different situations during the games, including the numerical change cases where the attackers try to end their attacks positively by expanding the playing areas with opening defensive gaps and by obtaining many chances of corrections against the opponents' goals and not ending the attack except they make sure they will score.

The researchers also attribute that some of the participating teams have developed methods to benefit during the numerical change (defensive and offensive) through the use of offensive lineups and formations that would avoid the defects of numerical change cases of all kinds, and the researchers attributes this to the teams which overcome the number inferiority sometimes where the team tries to compensate the number inferiority by increasing their movements on the opponents' goal circle and increasing the physical effort exerted, but this also requires high physical fitness, and in the case of numerical increase the team tries to end the attack positively and taking advantage of the defense gaps as a result of the opponent's number inferiority. The numerical increase or inferiority is important for the game results as they affect the team suspension whether negatively or positively.

\section{Conclusions and recommendations:}

\section{First: Conclusions:}

In light of the research objectives, questions, theoretical structure, sample, and in the context of the discussions mentioned above, and the questions within the research problem, the researchers concluded the following:

1- The highest efficiency degree of offensive tactical performance at the tournament level was for numerical equality cases, it reached 3.10 and $62.09 \%$, and the total cases were 469 cases with $47.6 \%$ of the total number of the tournament cases, while the lowest efficiency degree was for adding 2 players cases with an efficiency degree 2.50 and $50 \%$, and the total cases were 20 cases with $2 \%$ of the total number of the tournament cases.

2- When we generally observe the effectiveness of the offensive tactical performance of the numerical change cases for the participating teams, the cases of the numerical inferiority were the least efficient regarding the offensive tactical performance with a zero degree for the (C) level teams, while the highest efficiency degree was for the cases of numerical inferiority for the (A) level teams with an efficiency degree of 3.40 and $68 \%$.

3- The second period had taken advantage of the legal modifications to involve the goalkeeper's substitute and to make numerical change cases more than the other periods with 577 cases with $58.6 \%$ as well as the most efficiency degree with 3.07 and $61.39 \%$ of the total tournament cases.

4- When we observe the participating teams, we notice that the (B) level teams had taken advantage the most of the legal modifications by involving the goalkeeper's substitute to make numerical change cases with 456 substitutes of the total tournament 
cases with an efficiency degree of 3.18 and $63.55 \%$, while the (C) level teams were the had the least results with 199 cases out of the total number of the tournament cases with an efficiency degree of 2.95 and $58.99 \%$

\section{Second: Recommendations:}

Within the limits of the research community, selected sample, and in light of the research objectives, questions, and reached results, the researchers recommend the following:

1- Increasing the training to master the different offensive tactical lineups and formations in different situations in the match.

2- Developing the individual and group offensive performance and depending on action, not reaction to attract the defender's attention outside the finishing zone or to make a legal fault that ends up with a penalty throw.

3- Training the players to take advantage of the numerical change cases by designing compulsory training and technical positions during the friendly trainings and matches to implement them in the official matches.

4- Using different offensive lineups at critical times in a match whenever the team has numerical inferiority, equality or increase by practicing them and gaining experience through training and experimental matches.

\section{References:}

\section{Arabic references:}

1 Ahmed Gaber El-Merghani : Analysis of the tactical performances of the Ahmed (2014) numerical change cases for the top-level teams in handball, Master's thesis, Faculty of Physical Education for Boys, Alexandria University

2 Ekrami Mohamed Hamza Defensive style by attacking and its (2012) relationship to the results of top-level teams in handball, unpublished Master's thesis, Faculty of Physical Education, Alexandria University

3 Akram Kamel Ibrahim (2000) : Analytical study of the offensive and defensive lineups of the national handball team and its relationship to the match results in the Atlanta Olympic games, Master's thesis, Faculty of Physical Education,

4 Amany Hussein Mohamed : The mutual effect of offensive and defensive (2005) tactics on the effectiveness of the organized attack of the finishing phase in handball matches for men, PhD thesis, Faculty of 
Physical Education for Girls, Alexandria University.

5 Hassan El-Sayed Mansour : The effectiveness of some offensive Abdullah (2017) performances for top-level teams in the first and last ten minutes in handball matches, Master's thesis, Faculty of Physical Education for Boys, Abu Qir, Alexandria University.

6 Gamal Alaa-Eldin and Nahed : Metrological basis for evaluating the physical, Anwar El-Sabbagh (2007)

7 Tarek Lotfy Zahran (2004) : Development of the player's motor frequency during the organized attack in handball, $\underline{\mathrm{PhD}}$ thesis, Faculty of Physical Education for Boys, Alexandria University.

8 Adel Ibrahim Ahmed (2000) : Analysis of linear performance during numerical change in handball matches, published research, Scientific Journal of Physical Education and Sports, No. 19.

9 Abdel-Fattah Mohamed Abdullah (1979)

: The relationship between the sociometric structure of the team and some offensive tactical stations, unpublished $\mathrm{PhD}$ thesis, Faculty of Physical Education, Alexandria University.

10 Abdel-Wahab Ghazi

: Handball, educational and training principles, Hammoudi (2008) first edition, House of Books and Documentation, Baghdad.

11 Amr Abdel-Fattah Hussein : Analytical study of defensive and offensive (2009) tactical formations and their relationship to the results of the 2007 World Handball Championship matches, $\mathrm{PhD}$ thesis, Faculty of Physical Education, Mansoura

12 Ali El-Beik and Shaaban : Training tactics in basketball, Mansha'at AlIbrahim (1995) Maaref, Alexandria.

13 Kamal El-Din Darwish and : Defense in handball, Book Publishing Center, Kadry Sayed Morsy and Emad Cairo.

El-Din Abbas (2002)

14 Mohamed Ashraf Mohamed : Speed of combined offensive tactical Kamel (2008) performances between African and European 
men's handball players, Scientific Journal of Physical Education and Sports, $35^{\text {th }}$ issue, July.

15 Mohamed Khaled Abdel- : Designing a test to guide the under 15 years Kader Hammouda and Hala handball beginners, the second international Youssef Mandour (2004) scientific conference for physical education and sports sciences, 5-7 October 2004, Faculty of Physical Education for Boys, Alexandria University.

16 Mohamed Khaled Abdel- : The attack in handball, Al-Deeb Press, Kader Hammouda and Yasser Alexandria. Mohamed Hassan Dabbour (2014)

17 Mohamed Shawky Keshk and : Studying the effect of plyometric exercises in Amrallah El-Bossaty (2002)

18 Marwan Ali Abdullah (2011) the horizontal and vertical directions on the explosive power and velocity compounds among some athletes, Journal of Theories and Applications, issue 24, Faculty of Physical Education, Alexandria University.

Analytical study of some defensive variables (defensive skills - special cases) and their effect on the match results in the 2011 World Men's Handball Championship in Sweden, Journal of Science and Arts of Physical Education, issue 34, Faculty of Physical Education, Assiut University.

19 Mounir Gerges (2004)

: Handball for All, Dar Al-Fikr Al-Arabi, $4^{\text {th }}$ edition, Cairo

20 Yasser Mohamed Hassan : Modern handball, $1^{\text {st }}$ edition, Dar Al-Fikr AlDabbour (1996) Arabi.

21 (2001)

22 (2015)

: The productivity of offensive tactical methods and defensive lineups for the Egyptian team and some international teams in handball matches of the 2001 World Cup in France, Journal of Theories and Applications, Faculty of Physical Education for Boys, issue 43.

: Tactics in handball, Dar Al-Fikr Al-Arabi.

\section{Foreign references:}


23 Dinko vuleta, Goran sporis, : Influence Of Attacking Efficiency On The Borise purgar, Zvonko Outcome Of Handball Matches In The Herceg and Zoran Milanovic 2012 Preliminary Round Of Mens Olimpic Games 2008 , Sport Science .

24 Felicia lidia radu, Beatrice abalasei 2015

25 Loan Rudi Priscaru 2013

26 Jürgen Perl1 2002

: Teame Handball 101 " Techniques, Tactics , and Drill

: Using The Overtaking Manoeuvre In High Performance Handball , Science Direct

: Antagonistic Adaptation Systems: An

Example of How to Improve

Understandingand Simulating Complex System Behaviourby Use of Meta-Models and On Line-Simulation, University of Mainz, Institutefor Computer Science, Chair of AppliedComputer Science.

27 Nenad Rogulj, Vatromir

: The Contribution Of Collective Attack Srhoj and Ljerka Srhoj (2004)

28 Peter kovacs 2002 Tactics In Differentiating Handball Score, Efficiency Faculty Of Natural Sciences, Mathematics and Education University of Split, Split, Croatia .

: Substation Tactics, Top ANDEBOL Symposium For Coaches . IHF , Portugal

29 VALERYI MELNYK', VIKTORIA PASICHNYK',

: Tactical attacking actions of competitive handball players with different VOLODYMYR LEVKIV1, VASYL KOVTSUN 2016 qualificationJournal of Physical Education and Sport @ (JPES), 16(1), Art 13, pp. 77 83,2016

online ISSN: 2247 - 806X; p-ISSN: 2247 8051; ISSN - L = 2247 - 8051 (C) JPES 